\title{
Isolation and Characterization of Bifidobacterium longum subsp. longum BCBL-583 for Probiotic Applications in Fermented Foods
}

\author{
Da Hye $\mathrm{Yi}^{1 \dagger}$, You-Tae Kim ${ }^{1 \dagger}$, Chul-Hong Kim ${ }^{1,2}$, Young-Sup Shin ${ }^{2}$, and Ju-Hoon Lee ${ }^{1 *}$ \\ ${ }^{1}$ Department of Food Science and Biotechnology, Graduate School of Biotechnology, Kyung Hee University, Yongin 17104, Republic of Korea \\ ${ }^{2}$ Food Research Center, Binggrae Co., Ltd, Namyangju 12253, Republic of Korea
}

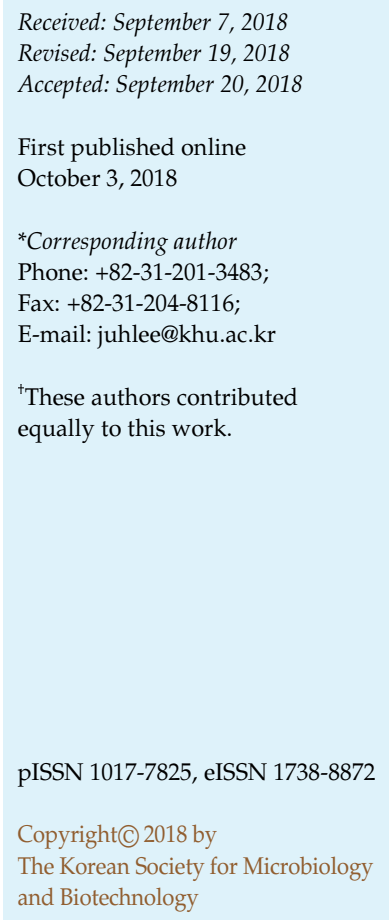

\begin{abstract}
Recent human gut microbiome studies have supported that the genus Bifidobacterium is one of the most beneficial bacteria for human intestinal health. To develop a new probiotic strain for functional food applications, fourteen fecal samples were collected from healthy Koreans and the strain BCBL-583 was newly selected and isolated from a 25-year-old Korean woman's fecal sample using the selective medium for Bifidobacterium. Subsequent fructose-6-phosphate phosphoketolase (F6PPK) test and 16S rRNA gene sequencing analysis of the strain BCBL-583 confirmed that it belongs to B. longum subsp. longum. The stress resistance tests showed that it has oxygen and heat tolerance activities (5- and 3.9-fold increase for $24 \mathrm{~h}$ at 60 and $120 \mathrm{rpm}$, respectively; $78.61 \pm 6.67 \%$ survival rate at $45^{\circ} \mathrm{C}$ for $24 \mathrm{~h}$ ). In addition, gut environment adaptation tests revealed that this strain may be well-adapted in the gut habitat, with gastric acid/bile salt resistance $(85.79 \pm 1.53 \%$, survival rate under $6 \mathrm{~h}$ treatments of gastric acid and bile salt) and mucin adhesion $(73.72 \pm 7.36 \%$ ). Furthermore, additional tests including cholesterol lowering assay showed that it can reduce $86.31 \pm 1.85 \%$ of cholesterol. Based on these results, B. longum BCBL-583 has various stress resistance for survival during food processing and environmental adaptation activities for dominant survival in the gut, suggesting that it could be a good candidate for fermented food applications as a new probiotic strain.
\end{abstract}

Keywords: Bifidobacteria, probiotics, bile salt resistance, mucin adhesion, cholesterol lowering
Since the first isolation of the genus Bifidobacterium from the feces of breast-fed infants in 1899 by Henri Tissier [1], it has been known to be one of the major genera in the human gastrointestinal tract [2]. Bifidobacteria are Gram-positive, non-motile, and strictly anaerobic bacteria with bifid or irregular rod shapes. They have been widely recognized as beneficial bacteria for promotion of human intestinal health [3]. These potential health benefits of Bifidobacteria include prevention of diarrhea [4], establishment of a healthy microbiota in pre-matured infants [5], alleviation of constipation [6], lactose intolerance [7], cholesterol reduction [8], gut immune stimulation [9], and cancer prevention [10]. However, while the composition rate of bifidobacteria in infant fecal microbiota is up to $96 \%$, it is lower, at $19 \%$, in adult fecal microbiota, suggesting that supplementation of bifidobacteria is required to maintain the adult gut health [11]. Therefore, various commercial bifidobacteria have been developed and supplemented in many fermented dairy products. Interestingly, the clinical feeding study of commercial bifidobacteria revealed that they may not colonize and survive in the human intestinal environment, probably due to the strain attenuation by loss of competitive fitness against other intestinal bacteria during commercial fermentation [12]. To take advantage of the health-benefiting effects of bifidobacteria in the gut, B. longum BCBL-583 was newly isolated from a healthy Korean fecal sample and characterized by various evaluation tests to validate its probiotic effects, such as stress resistance tests, gut environment adaptation assays, and additional health promotion functions. This newly isolated and scientifically evaluated probiotic strain may be a good candidate for various food applications to enhance 
the gut health of Koreans.

To isolate Korean-oriented bifidobacteria, fourteen fecal samples were collected from healthy Koreans and 753 strains were selected and isolated using BIM-25 bifidobacteria selective medium [13] under anaerobic incubation at $37^{\circ} \mathrm{C}$ for $24 \mathrm{~h}$ (data not shown). Among them, the strain BCBL583 was selected by prescreening with simple oxygen tolerance test for further probiotic evaluation tests. To identify this strain, fructose-6-phosphate phosphoketolase (F6PPK) test [14] and 16S rRNA gene sequencing analysis with NCBI BLASTN program [15] were performed. Their results substantiated that this strain belongs to $B$. longum subsp. Longum (data not shown).

Bifidobacteria are one of the most important probiotics to endow the specific health promoting effects in fermented food products. However, food processing procedures are too tough for probiotics to survive in this condition. Therefore, stress tolerance activities are generally required for survival during food processing. The survival rate of the selected B. longum BCBL-583 was evaluated under oxygen and heat stress conditions. Oxygen tolerance test was conducted in two different ways with the incubation at $37^{\circ} \mathrm{C}$ for $24 \mathrm{~h}$ : Static incubation on MRS agar plate without anaerobic condition and broth culture incubation with shaking at 60 or $120 \mathrm{rpm}$ [16]. After incubation, numerous colonies were observed on the agar plates. In addition, the optical density of each broth culture was monitored at $595 \mathrm{~nm}$ wavelength $\left(\mathrm{OD}_{595} \mathrm{~nm}\right)$. While initial $\mathrm{OD}_{595} \mathrm{~nm}$ was $0.120 \pm 0.02$ at $0 \mathrm{~h}$, it increased to $0.602 \pm 0.07$ at $60 \mathrm{rpm}$ and $0.470 \pm 0.06$ at $120 \mathrm{rpm}$ after $24 \mathrm{~h}$ shaking incubation, suggesting that $B$. longum BCBL-583 has oxygen tolerance activity (Fig. 1A). In addition, a heat tolerance test was performed as a previously published protocol [17]: (1) anaerobic incubation for $12 \mathrm{~h} \mathrm{(2)} \mathrm{heat} \mathrm{shock} \mathrm{at} 42^{\circ} \mathrm{C}, 45^{\circ} \mathrm{C}$, and $60^{\circ} \mathrm{C}$ for $3 \mathrm{~h}$, respectively (3) recovery at $37^{\circ} \mathrm{C}$ for $12 \mathrm{~h}$ (4) determination of absorbance at $595 \mathrm{~nm}$ wavelength. While $>99 \%$ of BCBL-583 was recovered after both $42^{\circ} \mathrm{C}$ and $45^{\circ} \mathrm{C}$ heat shock conditions, only $<30 \%$ of the strain survived after $60^{\circ} \mathrm{C}$ heat shock, suggesting that it may have moderate tolerance activity to temperature stress conditions. Based on this result, long-term heat tolerance activity of BCBL-583 at $45^{\circ} \mathrm{C}$ was determined. After incubation at $45^{\circ} \mathrm{C}$ for $24 \mathrm{~h}$ without recovery step, its optical densities at 595 $\mathrm{nm}$ wavelength were compared. Comparing $\mathrm{OD}_{595} \mathrm{~nm}$ at $37^{\circ} \mathrm{C}$ for $24 \mathrm{~h}, \mathrm{BCBL}-583$ showed viability of $78.61 \pm 6.67 \%$ at $45^{\circ} \mathrm{C}$. This result suggests that it is stable and heattolerant even at long-term heat stress conditions, indicating that it may be suitable for further commercial applications (Fig. 1B).
A

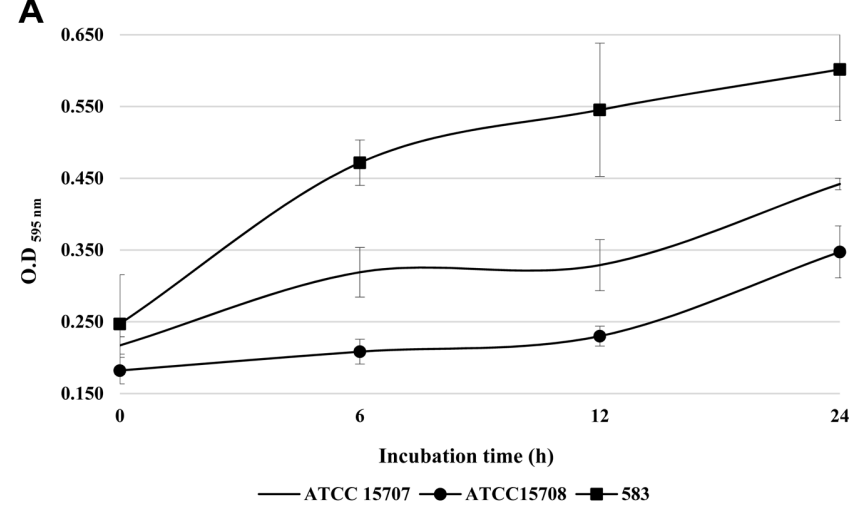

B

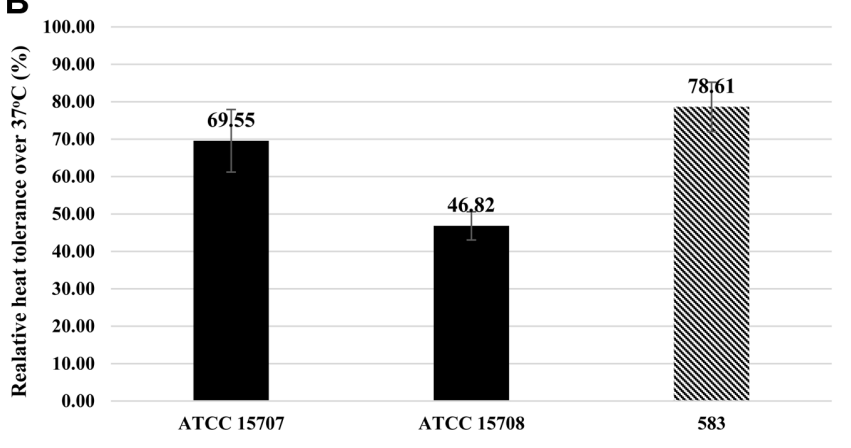

Fig. 1. Oxygen and heat tolerance tests for stress resistance with B. longum BCBL-583 and B. longum subsp. longum type strains, ATCC 15707 and ATCC 15708.

(A) Growth curves of three strains with shaking of $60 \mathrm{rpm}$ at $37^{\circ} \mathrm{C}$ for $24 \mathrm{~h}$. (B) Comparative $24 \mathrm{~h}$ heat tolerance test between $45^{\circ} \mathrm{C}$ and $37^{\circ} \mathrm{C}$. Error bars indicate standard deviations.

To survive in the human intestinal environment, gastric acid/bile salt tolerance and mucin layer adhesion may be important. Therefore, gastric acid/bile salt tolerance and mucin adhesion activities of BCBL-583 were determined. Gastric acid/bile salt test were conducted using a previously published procedure [18]: (1) bile salt exposure at $37^{\circ} \mathrm{C}$ for $3 \mathrm{~h}$ (2) PBS washing (3) gastric acid exposure at $37^{\circ} \mathrm{C}$ for $3 \mathrm{~h}$ (4) viable cell count after incubation on MRS agar plate at $37^{\circ} \mathrm{C}$ for $24 \mathrm{~h}$. The survival rate of BCBL-583 was $85.79 \pm$ $1.53 \%$ in gastric acid/bile salt, which is similar to type strains, B. longum ATCC 15707 and 15708 (Fig. 2A). This result indicates that BCBL-583 may survive in the passages of the stomach and intestinal environments. In addition to survival in the digestive organs, adhesion to mucin surface layers is also important for colonization and propagation of bifidobacteria in the intestinal environment. After attachment of mucin (Sigma, Germany) on the surface of 96-well plates at $4^{\circ} \mathrm{C}$ for $12 \mathrm{~h}$, BCBL- 583 cells were added to the plate and incubated at $37^{\circ} \mathrm{C}$ for $3 \mathrm{~h}$. The number of attached cells was 
A

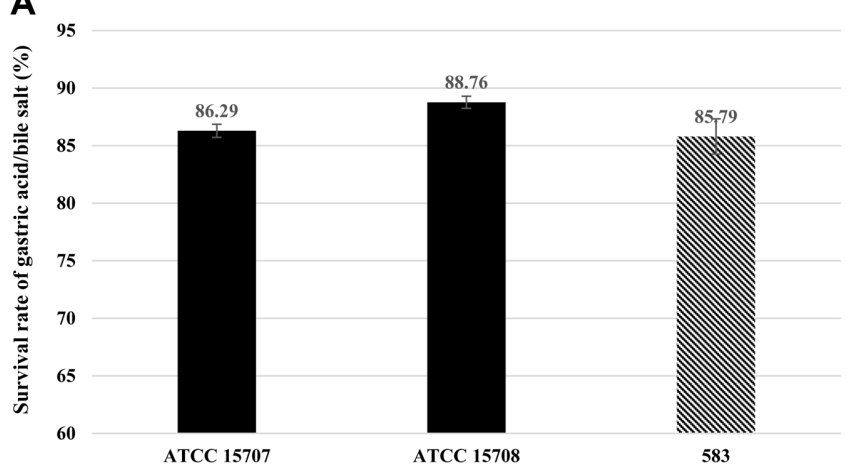

B

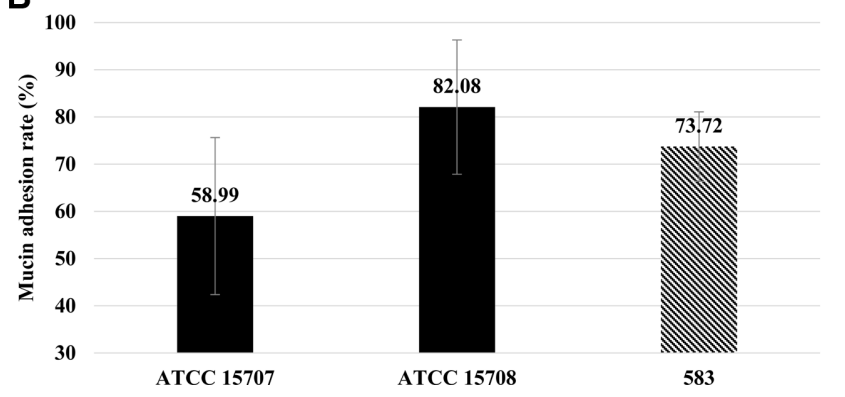

Fig. 2. Intestinal adaptation test of gastric acid/bile salt tolerance and mucin adhesion test with B. longum BCBL-583 and B. longum subsp. longum type strains, ATCC 15707 and ATCC 15708.

(A) Survival rate under $6 \mathrm{~h}$ treatments of bile salt (Pancreatin $0.1 \%$ $(\mathrm{w} / \mathrm{v})$, Bile $0.3 \%(\mathrm{w} / \mathrm{v})$, final $\mathrm{pH} 8.0)$ and gastric juice $(125 \mathrm{mM} \mathrm{NaCl}$, $7 \mathrm{mM} \mathrm{KCl}, 45 \mathrm{mM} \mathrm{NaHCO}, 3 \mathrm{~g} / 1$ pepsin, final $\mathrm{pH} 2.5$ adjusted with $5 \mathrm{~N} \mathrm{HCl}$ ). (B) Mucin adhesion test with $10 \mathrm{mg} / \mathrm{ml}$ mucin (Type 3 porcine gastric mucin). Error bars indicate standard deviations.

determined with difference between viable cell number in the control culture and detached viable cell number in the PBS buffer after washing $[17,19]$. The attachment rate of B. longum BCBL-583 was $73.72 \pm 7.36 \%$, which is a higher rate than that of ATCC $15707(58.99 \pm 16.65 \%)$, but a lower rate than that of ATCC $15708(82.08 \pm 14.22 \%)$ (Fig. 2B). This result suggests that BCBL-583 can survive during the passage of digestive organs and colonize in the mucosal cell surface layer of the human gut.

Because it is known that accumulation of excessive cholesterol in the blood stream may cause cardiovascular disease, concentration of cholesterol needs to be controlled. Interestingly, it was previously reported that bifidobacteria can assimilate cholesterol into their cell membranes [20]. To evaluate the cholesterol lowering activity of BCBL-583, it was cultured with $250 \mathrm{mM}$ cholesterol in MRS broth medium and incubated at $37^{\circ} \mathrm{C}$ for $24 \mathrm{~h}$. After incubation,

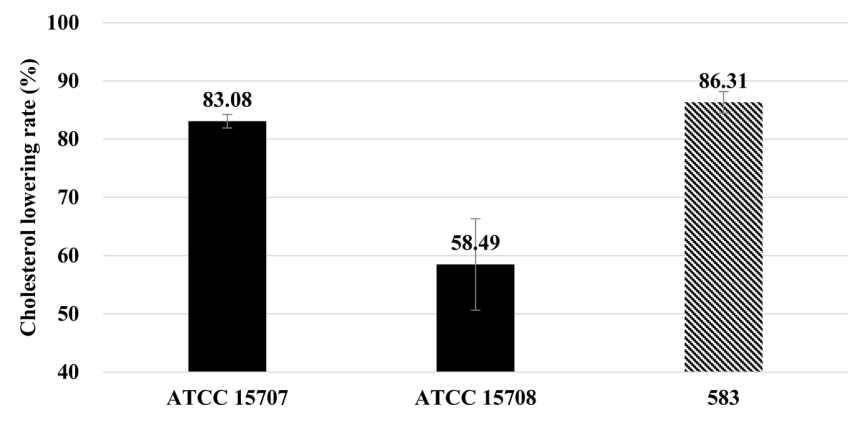

Fig. 3. Cholesterol lowering assay of B. longum BCBL-583 and B. longum subsp. longum type strains, ATCC 15707 and ATCC 15708 at $37^{\circ} \mathrm{C}$ for $24 \mathrm{~h}$.

All experiments were performed in triplicate. Error bars indicate standard deviations.

the remaining cholesterol in the culture was determined using Total Cholesterol Assay Kit (Cell Biolabs Inc., USA). This result showed that $B$. longum BCBL-583 lowered up to $86.31 \pm 1.85 \%$ of cholesterol in the culture, indicating its cholesterol lowering activity (Fig. 3). In addition, culture supernatant of BCBL-583 showed anti-Helicobacter pylori activity (diameter of inhibition zone, $16 \pm 0.0 \mathrm{~mm}$ ), comparing $15 \mathrm{mg} / \mathrm{ml}$ lactoferrin as a positive control $(18.5 \pm 2.12 \mathrm{~mm})$ [21], suggesting that it can inhibit the growth of $H$. pylori. Furthermore, gut immune stimulation activity of BCBL-583 was determined using Caco- 2 cells. To evaluate this activity, $10^{8} \mathrm{CFU} / \mathrm{ml}$ of viable or dead BCBL-583 cells were added to Caco-2 cell culture and incubated for $24 \mathrm{~h}$. After incubation, TNF- $\alpha$, IL- 6 , IL- 8 , and IL-10 of Caco- 2 cell culture supernatants were quantified using ELISA kit (Komabiotech, South Korea). These cytokines were mainly secreted by dead BCBL-583 cells (TNF- $\alpha, 10.55 \pm 6.00 \mathrm{pg} / \mathrm{ml}$; IL-6, $4.44 \pm 2.76$ pg/ml; IL-8, $44.28 \pm 3.89$ pg/ml; IL-10, 6.11 $\pm 1.7 \mathrm{pg} / \mathrm{ml}$ ), suggesting that BCBL-583 has immune stimulation activity. Subsequent immune response assay with RAW 264.7 macrophage cells and dead BCBL-583 cells $\left(10^{8} \mathrm{CFU} / \mathrm{ml}\right)$ substantiated this activity (TNF- $\alpha, 57.32 \pm$ $5.96 \mathrm{pg} / \mathrm{ml}$; IL-6, $16.08 \pm 3.7 \mathrm{pg} / \mathrm{ml})$.

Therefore, the new probiotic strain, B. longum BCBL-583 revealed all required properties regarding survival and colonization abilities in the human gut environment as well as probiotic effects including cholesterol reduction, anti$H$. pylori activity, and gut immune stimulation, suggesting that it can be a good candidate as a new probiotic strain of bifidobacteria for further probiotic applications in food industries. The GRAS (Generally Recognized As Safe) state of BCBL-583 support this. However, further in vivo evaluation tests of this strain to overcome various hurdles 
may still be required for successful industrial applications as a new functional probiotic component in the near future.

\section{Acknowledgements}

This research was supported by Food Research Center, Binggrae Co., Ltd.

\section{Conflict of Interest}

The authors have no financial conflicts of interest to declare.

\section{References}

1. Tissier H. 1899. Le bacterium coli et la reaction chromophile d'escherich. Crit. Rev. Soc. Biol. 51: 943-945.

2. O'Callaghan A, van Sinderen D. 2016. Bifidobacteria and their role as members of the human gut microbiota. Front Microbiol. 7:925.

3. Lee J-H, O'Sullivan DJ. 2010. Genomic insights into bifidobacteria. Microbiol. Mol. Biol. Rev. 74: 378-416.

4. Tissier H. 1906. Traitement des infections intestinales par la méthode de transformation de la flore bactérienne de l'intestin. Compt. Rend Soc. Biol. 60: 359-361.

5. Li Y, Shimizu T, Hosaka A, Kaneko N, Ohtsuka Y, Yamashiro Y. 2004. Effects of Bifidobacterium breve supplementation on intestinal flora of low birth weight infants. Pediatr. Int. 46: 509-515.

6. Agrawal A, Houghton L, Morris J, Reilly B, Guyonnet D, Feuillerat NG, et al. 2009. Clinical trial: the effects of a fermented milk product containing Bifidobacterium lactis DN173010 on abdominal distension and gastrointestinal transit in irritable bowel syndrome with constipation. Aliment Pharmacol. Ther. 29: 104-114.

7. Jiang T, Mustapha A, Savaiano DA. 1996. Improvement of lactose digestion in humans by ingestion of unfermented milk containing Bifidobacterium longum. J. Dairy Sci. 79: 750-757.

8. Ataie-Jafari A, Larijani B, Majd HA, Tahbaz F. 2009. Cholesterol-lowering effect of probiotic yogurt in comparison with ordinary yogurt in mildly to moderately hypercholesterolemic subjects. Ann. Nutr. Metab. 54: 22-27.

9. Kim N, Kunisawa J, Kweon M-N, Ji GE, Kiyono H. 2007. Oral feeding of Bifidobacterium bifidum (BGN4) prevents CD4+ CD45RBhigh $\mathrm{T}$ cell-mediated inflammatory bowel disease by inhibition of disordered $\mathrm{T}$ cell activation. Clin. Immunol. 123: 30-39.

10. Sekine K, Toida T, Saito M, Kuboyama M, Kawashima T, Hashimoto Y. 1985. A new morphologically characterized cell wall preparation (whole peptidoglycan) from Bifidobacterium infantis with a higher efficacy on the regression of an established tumor in mice. Cancer Res. 45: 1300-1307.

11. Ishibashi N, Yaeshima T, Hayasawa H. 1997. Bifidobacteria: their significance in human intestinal health. Mal. J. Nutr. 3: 149-159.

12. Lee J-H, Karamychev V, Kozyavkin S, Mills D, Pavlov A, Pavlova N, et al. 2008. Comparative genomic analysis of the gut bacterium Bifidobacterium longum reveals loci susceptible to deletion during pure culture growth. BMC Genomics 9: 247.

13. Munoa F, Pares R. 1988. Selective medium for isolation and enumeration of Bifidobacterium spp. Appl. Environ. Microbiol. 54: 1715-1718.

14. Gavini F, Van Esbroeck M, Touzel J, Fourment A, Goossens H. 1996. Detection of fructose-6-phosphate phosphoketolase (F6PPK), a key enzyme of the bifid-shunt, in Gardnerella vaginalis. Anaerobe 3: 191-193.

15. Altschul SF, Gish W, Miller W, Myers EW, Lipman DJ. 1990. Basic local alignment search tool. J. Mol. Biol. 215: 403-410.

16. Grasso EM, Somerville JA, Balasubramaniam VM, Lee K. 2010. Minimal effects of high-pressure treatment on Salmonella enterica serovar Typhimurium inoculated into peanut butter and peanut products. J. Food Sci. 75: E522-526.

17. Azcarate-Peril M, Tallon R, Klaenhammer T. 2009. Temporal gene expression and probiotic attributes of Lactobacillus acidophilus during growth in milk. J. Dairy Sci. 92: 870-886.

18. Grimoud J, Durand H, Courtin C, Monsan P, Ouarné F, Theodorou $\mathrm{V}$, et al. 2010. In vitro screening of probiotic lactic acid bacteria and prebiotic glucooligosaccharides to select effective synbiotics. Anaerobe 16: 493-500.

19. Ruas-Madiedo P, Gueimonde M, Margolles A, de los ReyesGavilán CG, Salminen S. 2006. Exopolysaccharides produced by probiotic strains modify the adhesion of probiotics and enteropathogens to human intestinal mucus. J. Food Prot. 69: 2011-2015.

20. Dambekodi P, Gilliland S. 1998. Incorporation of cholesterol into the cellular membrane of Bifidobacterium longum. J. Dairy Sci. 81: 1818-1824.

21. Sgouras D, Maragkoudakis P, Petraki K, Martinez-Gonzalez B, Eriotou E, Michopoulos S, et al. 2004. In vitro and in vivo inhibition of Helicobacter pylori by Lactobacillus casei strain Shirota. Appl. Environ. Microbiol. 70: 518-526. 